\title{
Syntheses of Coordination Compounds of 2-Amino-3-Methylbutanoic Acid Their Mixed Ligand Complexes and Antibacterial Activities
}

\author{
Temitayo 0. Aiyelabola1 ${ }^{*}$, Iyanuoluwa E. Okunade1, Johan H. L. Jordaan ${ }^{2}$, Daniel P. Otto² \\ ${ }^{1}$ Department of Chemistry, Obafemi Awolowo University Ile-Ife, Osun State, Nigeria \\ ${ }^{2}$ Research Focus Area for Chemical Resource Beneficiation, Laboratory for Analytical Services; North-West University, \\ Potchefstroom, South Africa \\ Email: ^taiyelabola@gmail.com, Johan.Jordaan@nwu.ac.za
}

How to cite this paper: Aiyelabola, T.O., Okunade, I.E., Jordaan, J.H.L. and Otto, D.P. (2020) Syntheses of Coordination Compounds of 2-Amino-3-Methylbutanoic Acid Their Mixed Ligand Complexes and Antibacterial Activities. Advances in Biological Chemistry, 10, 67-85.

https://doi.org/10.4236/abc.2020.103006

Received: March 20, 2020

Accepted: June 1, 2020

Published: June 4, 2020

Copyright $\odot 2020$ by author(s) and Scientific Research Publishing Inc. This work is licensed under the Creative Commons Attribution International License (CC BY 4.0).

http://creativecommons.org/licenses/by/4.0/

\section{(c) (i) Open Access}

\begin{abstract}
Coordination compounds of 2-amino-3-methylbutanoic acid were synthesized with chromium(III) and oxovanadium(IV) ions. M:L; 1:2. Adducts of these complexes using 1,10-phenantroline and ethylenediamine were further synthesized, M:L, (1:2). These compounds were characterized using electronic, infra-red spectrophotometry, magnetic susceptibility measurement and percentage metal analyses. The zones of inhibition and minimum inhibitory concentrations of the compounds against eight microbes were studied. The results obtained indicated an octahedral geometry for the $\mathrm{Cr}$ (III) complexes, indicative of additional coordination of two water molecules. On the other hand a square pyramid geometry was obtained for the binary oxovanadium complex and its 1,10-phenantroline adduct. However, for the oxovanadium ethylenediamine adduct a distorted octahedral geometry was proposed. The result for the antibacterial studies indicated that both mixed ligand complexes of 1,10-phenantroline exhibited good antibacterial activity, and in some cases better activity than the standard, streptomycin.
\end{abstract}

\section{Keywords}

Coordination Compounds, 2-Amino-3-Methylbutanoic Acid, Mixed Ligand Complexes, Minimum Inhibitory Concentration, 1,10-Phenantroline, Ethylenediamine

\section{Introduction}

As a result of the vast diversity of transition metal coordination chemistry, prospects for the design of coordination compounds in more recent times have 
been a subject of great interest [1]. The pharmacological activity of these metal compounds depends on the metal ion, ligands and the structure of the compounds. These factors are partly responsible for the ability of these coordination compounds, to locate the proper target site of activity and as a consequence their pharmacological activity [1] [2] [3] [4]. It is known that certain metal ions penetrate through bacteria cell walls, in the form of complexes, into the cell and inactivate certain enzymes, thus killing such bacteria [5] [6]. Furthermore, prior reports have also indicated that the efficacies of various therapeutic agents are often enhanced upon coordination with a suitable metal ion [7] [8] [9].

A class of coordination compounds being more studied in recent times is the mixed ligand complexes. These complexes have at least two different ligands coordinated to a metal ion [9] [10] [11] [12]. The pharmacological activity of these mixed ligand complexes is highly dependent on the nature of the metal ions and the donor sequence of the ligands. This is because different ligands exhibit different structural and biological properties [13] [14]. Their increased activity may be ascribed to a synergistic or additive activity of the differing ligands on the metal ion and the complex as a whole, thereby enhancing the activity of the complex [13]. Moreover, they may have the potential to thwart drug resistance [14]. They also have the potential for increased broad spectrum of activity [15]. A versatile ligand often used in the syntheses of mixed ligand complexes is 1,10-phenantroline, it is a heterocyclic organic compound. It is rigid and its insertion within cyclic and acyclic structures can impact to the resulting complex a high degree of pre-organization [16]. The antimicrobial activity of 1,10-phenantroline is also well established [17] [18]. Ethylenediamine is also another well known ligand used in coordination chemistry. Reports have shown that numerous bio-active compounds and drugs contain the $\mathrm{N}-\mathrm{CH}_{2}-\mathrm{CH}_{2}-\mathrm{N}$ linkage, which exists in ethylenediamine [19].

In spite of a huge number of antibiotics and chemotherapeutics available for medical use, there is still an outbreak of diseases caused by different pathogenic bacteria and the development of resistance to antibiotics [6] [9] [14]. Researchers are as a consequence searching for new antibacterial agents. Furthermore, earlier studies have also shown that some coordination compounds of biologically important compounds such as amino acids exhibited promising antimicrobial activities on chelation [6] [20] [21]. As a result of the probable enhanced antibacterial activity of mixed ligand complexes it was therefore considered to synthesize coordination compounds of 2-amino-3-methylbutanoic acid (Figure 1) with chromium(III) and oxovanadium(IV). Their mixed ligand complexes with 1,10-phenantroline and ethylenediamine (Figure 2 and Figure 3), M:L1:L2 and M:L1:L3 metal ligand ratio (1:1:1) (where $\mathrm{M}=\mathrm{Cr}(\mathrm{III})$ or $\mathrm{VO}(\mathrm{IV}), \mathrm{L} 1$ = 2-amino-3-methylbutanoic acid, L2 = 1,10-phenantroline, L3 = ethylenediamine) were also synthesized. These compounds were characterized using infra-red, electronic and atomic absorption spectroscopy and magnetic susceptibility measurement. The antibacterial assays of the synthesized compounds was carried out 


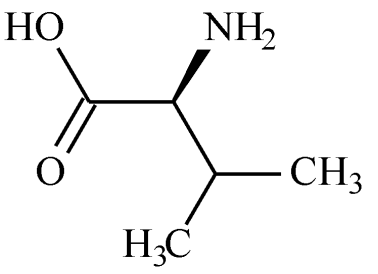

Figure 1. 2-amino-3-methylbutanoic acid, (L1).

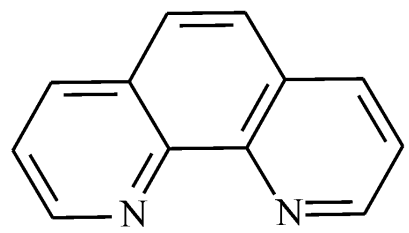

Figure 2. 1,10-phenantroline (L2).<smiles>NCCN</smiles>

Figure 3. Ethylenediamine (L3).

using disc diffusion agar method to determine their zones of inhibitions against eight microbes; three gram positive and five gram negative bacteria. The minimum inhibition concentrations of the more active compounds were also obtained.

\section{Materials and Method}

\subsection{General}

All materials used are of high analytical grade. Melting points were determined in an open capillary tube on a Gallenkamp (Variable heater) melting point apparatus. The infrared spectra of all synthesized product and their ligands were obtained at the Centre for Energy Research and Development Obafemi Awolowo University Ile-Ife, Osun State. Magnetic susceptibility measurement of the metal complexes was obtained at the Department of Chemistry, Kwara State University Ilorin, Nigeria. The electronic spectra, of all the compounds, were obtained in solution, in the wavelength range $400-1000 \mathrm{~nm}$ at the Department of Chemistry, Obafemi Awolowo University, Ile-Ife, Osun State Nigeria. The metal analyses for all synthesized compounds were obtained using atomic absorption spectroscopy at the Centre for Energy Research and Development Obafemi Awolowo University Ile-Ife, Osun state. The antimicrobial screening for all the complexes was carried out in the Department of Microbiology at Obafemi Awolowo University Ile Ife, Osun state. Nigeria.

The equations of the reactions are given in Equations (1)-(6).

$$
\begin{aligned}
\mathrm{CrCl}_{3}+2(\mathrm{~L} 1) & \rightarrow\left[\left(\mathrm{Cr}(\mathrm{L} 1)_{2}\left(\mathrm{H}_{2} \mathrm{O}\right)_{2}\right](\text { Compound 1) }\right. \\
\mathrm{CrCl}_{3}+\mathrm{L} 1+\mathrm{L} 2 & \rightarrow\left[\mathrm{Co}(\mathrm{L} 1)(\mathrm{L} 2)\left(\mathrm{H}_{2} \mathrm{O}\right)_{2}\right](\text { Compound } 2) \\
\mathrm{CrCl}_{3}+\mathrm{L} 1+\mathrm{L} 3 & \rightarrow\left[\mathrm{Co}(\mathrm{L} 1)(\mathrm{L} 3)\left(\mathrm{H}_{2} \mathrm{O}\right)_{2}\right](\text { Compound } 3) \\
\mathrm{VOSO}_{4}+2(\mathrm{~L} 1) & \left.\rightarrow \mathrm{VO}(\mathrm{L} 1)_{2}\right](\text { Compound } 4)
\end{aligned}
$$




$$
\left.\mathrm{VOSO}_{4}+\mathrm{L} 1+\mathrm{L} 3 \rightarrow \mathrm{VO}(\mathrm{L} 1)(\mathrm{L} 3)\left(\mathrm{H}_{2} \mathrm{O}\right)\right] \text { Compound 6) }
$$

where: $\mathrm{L} 1=2$-amino-3-methylbutanoic acid

L2 = 1,10-phenantroline; L3 = ethylenediamine.

\subsection{Syntheses of Compounds}

\subsubsection{Synthesis of Compound 1}

An aqueous solution of chromium(III) chloride hexahydrate $(1.59 \mathrm{~g}, 0.01 \mathrm{M})$ was poured into a flat bottom flack and was heated with stirring. To this was added, drop-wise, an aqueous ethanolic solution of 2-amino-3-methylbutanoic acid $(2.36 \mathrm{~g}, 0.02 \mathrm{M})$. The reaction mixture was heated for $2 \mathrm{~h}$, during which a pink precipitate was obtained. This was filtered washed first with methanol then diethyl ether and dried in a desiccator.

Similar procedure was used for the preparation of the under listed complexes.

\subsubsection{Synthesis of Compound 2}

Chromium(III) chloride hexahydrate $(1.58 \mathrm{~g}, 0.01 \mathrm{M})$ in a flat bottom flask to which was added 2-amino-3-methylbutanoic acid (1.18 g; $0.01 \mathrm{M})$ and 1,10phenantroline $(1.80 \mathrm{~g}, 0.01 \mathrm{M})$ heated with stirring. This gave a dark green precipitate.

\subsubsection{Synthesis of Compound 3}

Chromium(III) chloride hexahydrate $(1.61 \mathrm{~g}, 0.01 \mathrm{M})$ to which 2-amino-3-methylbutanoic acid $(1.32 \mathrm{~g} ; 0.01 \mathrm{M})$ and ethane-1,2-diamine monohydrate $(0.78 \mathrm{~g}$, $0.01 \mathrm{M}$ ) was added and heated with stirring. This gave a light pink precipitate.

\subsubsection{Synthesis of Compound 4}

Vanadium(IV) oxide sulphate $(1.63 \mathrm{~g}, 0.01 \mathrm{M})$ and 2-amino-3-methylbutanoic acid $(2.38 \mathrm{~g} ; 0.02 \mathrm{M})$ gave a pink precipitate.

\subsubsection{Synthesis of Compound 5}

Vanadyl sulphate $(1.63 \mathrm{~g}, 0.01 \mathrm{M})$ to which was added 2-amino-3-methylbutanoic acid $(1.32 \mathrm{~g} ; 0.01 \mathrm{M})$ and 1,10-phenantroline $(1.83 \mathrm{~g}, 0.01 \mathrm{M})$, heated with stirring, gave a grey precipitate.

\subsubsection{Synthesis of Compound 6}

Vanadyl sulphate (1.65 g, $0.01 \mathrm{M})$, 2-amino-3-methylbutanoic acid (1.34 g; 0.01 $\mathrm{M})$ and ethylenediamine monohydrate $(0.79 \mathrm{~g}, 0.01 \mathrm{M})$, gave a grey precipitate.

\subsection{Antimicrobial Methodology}

\subsubsection{Zones of Inhibition}

The organisms used were three Gram-positive and five Gram-negative bacteria. The agents were dissolved in water at room temperature or hot water as appropriate to give a concentration of $40 \mathrm{mg} / \mathrm{mL}$. The resulting solutions were used to soak sterile Whatman No 2 discs (diameter of $6 \mathrm{~mm}$ ) and allowed to dry in an 
oven at $50^{\circ} \mathrm{C}$. The discs were then utilized to determine antibacterial as previously described by Aiyelabola et al. 2012 [22]. Discs that were impregnated with streptomycin were used as positive controls for bacteria. Zones of inhibition were used as indices of antimicrobial actions.

\subsubsection{Minimum Inhibitory Concentration Determination}

The determination of the minimal inhibitory concentration (MIC) for the antibacterial activities of three of the compounds and standard drugs were evaluated using the microdilution method, using an adaptation of the methodology as described by Pasdar, $\mathrm{H}$ and co-worker, 2017 [23]. Each test compound and standard drug individually was prepared in aqueous ethanol to obtain $10 \mu \mathrm{g} / \mathrm{mL}$ concentrations (stock solution). The aim of the broth micro-dilution method was the evaluation of the lowest concentration of the examined antibacterial agent to inhibit the visible growth of the microorganism being investigated. Muller-Hinton Broths (MHB) was used as bacterial nutrients. The inoculum size of all strains was adjusted to $1.5 \times 10^{8} \mathrm{CFU} / \mathrm{mL}$ using $0.5 \mathrm{McF}$ arland standard solutions for each antibacterial compound and standard drug (streptomycin). Fifteen tubes of $5 \mathrm{~mL}$ volume were used in 3 rows such that each row contained 5 tubes. Afterwards, $1 \mathrm{~mL}$ of Muller-Hinton Broth (for Row 1 and 2) and $1 \mathrm{~mL}$ of standard drug broth (for row 3 ) were added in Tubes 1 - 5 in each row. Then, $1 \mathrm{~mL}$ of the antibacterial compound (stock solution) was added to the first tube in each row (for Row 1 and 2) and mixed. After mixing, $1 \mathrm{~mL}$ of the first tube in each row was serially carried over to the second tube in the same row, mixed and the content of the second tube was transferred to the third tube in each row. This serial dilution was repeated to Tube 4 in each of the rows and 1 $\mathrm{mL}$ of Tube 4 was discarded. Tube 4 had no bacteria and was used as a negative control. Tube 5, without antibacterial agent, was used as a positive control. Thus, the micro-dilution provided antibacterial concentrations of 5, 2.5, 1.75 and 0.875 $\mu \mathrm{g} / \mathrm{mL}$ respectively. Finally, $100 \mu \mathrm{L}$ of bacteria suspension was added to Tubes 1 - 3 and 5 in Rows 1 - 3 and were incubated for $24 \mathrm{~h}$ at $37^{\circ} \mathrm{C}$. The highest dilution of active sample to inhibit evident growth of the microorganism was expressed as the MIC [23].

\section{Result and Discussion}

\subsection{Physico-Chemical Properties}

The colour, percentage yield, percentage metal and melting points of the synthesized compounds are presented in Table 1 . The compounds showed a wide variety of colour from pink to grey. The compounds were obtained at good yield. Sharp melting points were obtained for the compounds suggesting the purity of the compounds. The compounds were fairly soluble in ethanol/water mixture and insoluble in most organic solvents. The percentage analysis for the compounds was obtained using atomic absorption spectroscopy/titremetric method. The results obtained are in good agreement with the calculated values; as 
Table 1. Some Physico-chemical Properties of the ligands and complexes.

\begin{tabular}{|c|c|c|c|c|c|c|c|}
\hline Compound & Proposed mol. Formula & $\begin{array}{l}\text { Proposed } \\
\text { m.wt }\end{array}$ & Colour & \%yield & $\begin{array}{l}\mathrm{Mp} / \mathrm{d} . \mathrm{t} \\
{ }^{\circ} \mathrm{C}\end{array}$ & $\begin{array}{c}\text { Magnetic moment } \\
(\mathrm{BM})\end{array}$ & $\begin{array}{c}\text { \%metal } \\
\text { Found (Cal.) }\end{array}$ \\
\hline L1 & $\mathrm{C}_{5} \mathrm{H}_{11} \mathrm{NO}_{2}$ & 117.15 & White & NA & 298 & NA & NA \\
\hline L3 & $\mathrm{C}_{2} \mathrm{H}_{8} \mathrm{~N}_{2}$ & 60.00 & Colourless & NA & NA & NA & NA \\
\hline 1 & {$\left[\left(\mathrm{Cr}(\mathrm{L} \mathbf{1})_{2}\left(\mathrm{H}_{2} \mathrm{O}\right)_{2}\right] \mathrm{Cl}\right.$} & 353.80 & Pink & 61.4 & 270 & 3.14 & $15.20(14.77)$ \\
\hline 2 & {$\left[\mathrm{Co}(\mathrm{L} 1)(\mathrm{L} 2)\left(\mathrm{H}_{2} \mathrm{O}\right)_{2}\right] \mathrm{Cl}_{2}$} & 455.20 & Deep green & 72.3 & 269 & 3.84 & $11.87(11.42)$ \\
\hline 4 & $\left.\mathrm{VO}(\mathrm{L} 1)_{2}\right]$ & 297.00 & Pink & 69.2 & 284 & 1.75 & $17.45(17.17)$ \\
\hline 5 & {$[\mathrm{VO}(\mathrm{L} 1)(\mathrm{L} 2)]_{2} \mathrm{SO}_{4}$} & 822.42 & Gray & 76.4 & 285 & 1.97 & $12.54(12.40)$ \\
\hline 6 & {$\left[\mathrm{VO}(\mathrm{L1})(\mathrm{L} 3)\left(\mathrm{H}_{2} \mathrm{O}\right)\right]_{2} \mathrm{SO}_{4}$} & 618.00 & Gray & 73.6 & 306 & 2.05 & $8.67(8.31)$ \\
\hline
\end{tabular}

such the results obtained corroborated the proposed composition of the compounds.

\subsection{Infra-Red}

\subsubsection{Ligand}

1) 2-amino-3-methylbutanoic acid: The spectrum of 2-amino-3-methylbutanoic acid exhibited characteristic vibrational frequency bands such as the $v(\mathrm{~N}-\mathrm{H})$ of the cationic $\mathrm{NH}_{3}^{+}$ion observed at $3400 \mathrm{~cm}^{-1}$ (Table 2). The spectrum further displayed bands at $1607 \mathrm{~cm}^{-1}$ and $1495 \mathrm{~cm}^{-1}$ which are consistent with the asymmetric and symmetric $\mathrm{COO}^{-}$stretching frequencies and both are typical vibrational frequencies of 2-amino-3-methylbutanoic acid [24] [25] [26].

2) 1,10-phenantroline: The spectrum for this compound elicited a band at $1588 \mathrm{~cm}^{-1}$ assignable to the $v(\mathrm{C}=\mathrm{N})[26]$.

3) Ethylenediamine: The infrared spectrum revealed a band at $3373 \mathrm{~cm}^{-1}$ which was ascribed to the $v(\mathrm{~N}-\mathrm{H})$ of the amine substituent of the ligand. Two other sharp bands were also observed at 1567 and $1403 \mathrm{~cm}^{-1}$, Table 2 and are ascribed to $v(\mathrm{C}-\mathrm{C}-\mathrm{N})$ and $v(\mathrm{C}-\mathrm{N})$ of $\mathrm{C}-\mathrm{C}-\mathrm{NH}_{2}$ bond vibration [24] [25] [26].

\subsubsection{Complexes}

Chromium complexes

1) Compound 1: A shift was observed to higher wave number for the $v(\mathrm{~N}-\mathrm{H})$ symmetric stretching frequency thus suggestive of deprotonation and hence coordination of the nitrogen atom of the amino moiety to the metal ion. This was supported by the $\mathrm{M}-\mathrm{N}$ stretching frequency observed at $612 \mathrm{~cm}^{-1}$ [24] [25] [26]. On the other-hand a shift was observed to higher wave number for the $\mathrm{COO}^{-}$symmetric stretching frequency and a shift to lower wave number for the $v_{\text {asym }}\left(\mathrm{COO}^{-}\right)$by $(80) \mathrm{cm}^{-1}$. Previous reports have suggested that this indicates coordination of the ligand to the metal ion. A difference of $219 \mathrm{~cm}^{-1}$ exists between both the $v_{\text {sym }}\left(\mathrm{COO}^{-}\right)$and $v_{\text {asym }}\left(\mathrm{COO}^{-}\right)$thus indicating the monodentate nature of the $\mathrm{COO}^{-}$substituent of the ligand in this complex. Corroborating the coordination via the oxygen atom is the $\mathrm{M}-\mathrm{O}$ band observed at $580 \mathrm{~cm}^{-1}$. Furthermore, evidence for the coordination of water molecule to the metal ion was provided by the bands observed at 2587, 1033 and $810 \mathrm{~cm}^{-1}$ assignable to $v(\mathrm{C}-\mathrm{OH}), v(\mathrm{C}-\mathrm{O})$ and $v(\mathrm{C}-\mathrm{O})$ bending and rocking vibrational frequencies [24] [25] [26]. 
Table 2. Relevant infrared spectra bands for the ligands and complexes $\left(\mathrm{cm}^{-1}\right)$.

\begin{tabular}{ccccccc}
\hline Compound & NH & COO & COO & C=N & M-N & M-O \\
\hline L1 & 3400 & 1607 & 1495 & - & - & - \\
L2 & - & - & - & 1588 & - & - \\
L3 & 3373 & 1567 & 1403 & - & - & - \\
$\mathbf{1}$ & 3424 & 1634 & 1415 & - & 612 & 580 \\
$\mathbf{2}$ & 3362 & 1635 & 1398 & 1506 & 562 & \\
$\mathbf{3}$ & 3390 & 1638 & 1411 & - & 632 & 536 \\
$\mathbf{4}$ & 3481 & 1653 & 1455 & - & 647 & 570 \\
$\mathbf{5}$ & 3444 & 1635 & 1399 & 1504 & 615 & 537 \\
$\mathbf{6}$ & 3365 & 1639 & 1400 & - & 672 & 568 \\
\hline
\end{tabular}

2) Compound 2: Evidence for coordination of the 2-amino-3-methylbutanoic acid in this mixed ligand complex was provided by the $v(\mathrm{~N}-\mathrm{H}), v_{\text {sym }}(\mathrm{COO})$ and $v_{\text {asym }}(\mathrm{COO})$ bands observed at 3362, 1635 and $1398 \mathrm{~cm}^{-1}$ respectively. Support for the formation of the mixed ligand and hence coordination of 1,10-phenantroline was observed by the shift in the $v(\mathrm{C}=\mathrm{N}), 82 \mathrm{~cm}^{-1}$ in comparison to that of the ligand, it should be noted that this was absent in the spectrum of 2-amino-3-methylbutanoic acid [24] [25] [26]. Absorption frequencies observed at 1032 and 1015 and attributable to $v(\mathrm{C}-\mathrm{O})$ suggest coordination of water to the metal ion [9] [24] [25] [26] [27].

3) Compound 3: For this mixed ligand complex evidence for coordination of the 2-amino-3-methylbutanoic acid was observed in the shift of the $v(\mathrm{~N}-\mathrm{H})$, $v_{\text {sym }}(\mathrm{COO})$ and $v_{\text {asym }}(\mathrm{COO})$. This were further corroborated by the $v(\mathrm{M}-\mathrm{N})$, $v(\mathrm{M}-\mathrm{O})$ bands [26]. The band observed at $1325 \mathrm{~cm}^{-1}$ was assigned to the $v(\mathrm{C}-$ $\mathrm{C}-\mathrm{N}$ ) of $\mathrm{C}-\mathrm{C}-\mathrm{NH}_{2}$ from ethylenediame. This indicated a shift of $95 \mathrm{~cm}^{-1}$ on coordination, thus indicative of coordination of the metal ion to the ligand. Additional coordination by water molecule was suggested by the appearance of the $v(\mathrm{C}-\mathrm{O})$ band and $v(\mathrm{M}-\mathrm{O})$ [24] [25] [26] [27].

\subsubsection{Vanadium Complexes}

1) Compound 4: Similar to the bis(2-amino-3-methylbutanoic acid)chromium (III) complex, a shift to high frequency was observed for the $v(\mathrm{~N}-\mathrm{H})$ stretching frequency by $81 \mathrm{~cm}^{-1}$ [26]. As such, this suggested the coordination of the nitrogen atom of the ligand to the metal ion. This was further supported by the $v(\mathrm{M}-\mathrm{N})$ observed at $637 \mathrm{~cm}^{-1}$. The spectrum also showed two sharp bands at 1653 and $1455 \mathrm{~cm}^{-1}$, which are assignable to characteristic $v_{\text {sym }}\left(\mathrm{COO}^{-}\right)$and $v_{\text {asym }}\left(\mathrm{COO}^{-}\right)$of the ligand. This indicated a shift in comparison to those of the free ligand. The difference of $197 \mathrm{~cm}^{-1}$ between both band frequencies suggests the monodentate nature of the ligand in this complex [9] [26]. Coordination of the oxygen atom of the carboxylate ion was also supported by the $v(\mathrm{M}-\mathrm{O})$ at 570 $\mathrm{cm}^{-1}$. A band observed at $950 \mathrm{~cm}^{-1}$ was attributed to $v(\mathrm{~V}=\mathrm{O})$, suggestive of the monomeric nature of the complex [28] [29] [30].

2) Compound 5: This spectrum exhibited a band at $3444 \mathrm{~cm}^{-1}$ ascribable to $v(\mathrm{~N}-\mathrm{H})$ of the amino substituent of 2-amino-3-methylbutanoic acid. Thus, sug- 
gesting coordination of the metal ion with the primary ligand, 2-amino-3-methylbutanoic acid. Coordination of the secondary ligand 1,10-phenantroline to the metal ion was suggested by the band observed at $1504 \mathrm{~cm}^{-1}$ attributable to $\mathrm{C}=\mathrm{N}$ stretching frequency of 1,10-phenantroline [26]. This indicated a shift by $84 \mathrm{~cm}^{-1}$ to higher wave number in relation with the free base. As such this serves to establish the formation of the mixed ligand complex. The band observed at $986 \mathrm{~cm}^{-1}$, assigned to $v(\mathrm{~V}=\mathrm{O})$ is indicative of the monomeric nature of the complex [28] [29] [30].

3) Compound 6: The $v(\mathrm{~N}-\mathrm{H})$ of the primary ligand was observed at 3365 $\mathrm{cm}^{-1}$. A broad band in the shape of a trough appeared at $2100 \mathrm{~cm}^{-1}$ and was attributed to the $v(\mathrm{C}-\mathrm{OH})$. This therefore, suggests coordination of a water molecule. Bands at 1639 and $1400 \mathrm{~cm}^{-1}$ were assigned to $v_{\text {sym }}\left(\mathrm{COO}^{-}\right)$and $v_{\text {asym }}\left(\mathrm{COO}^{-}\right)$of the ligand, 2-amino-3-methylbutanoic acid [24] [25] [26]. A sharp band at 1390 $\mathrm{cm}^{-1}$ corresponds to the $v(\mathrm{C}-\mathrm{C}-\mathrm{N})$ of $\mathrm{C}-\mathrm{C}-\mathrm{NH}_{2}$ bond vibration, of the secondary ligand. Two medium bands observed at 1230 and $1120 \mathrm{~cm}^{-1}$ were assigned to the $v(\mathrm{C}-\mathrm{N})$ of both the primary and secondary ligand [24] [25] [26]. The $v(\mathrm{M}-\mathrm{O})$ was observed at 672 and $612 \mathrm{~cm}^{-1}$, thus, supportive of coordination of the oxygen atom from the carboxylate substituent of the primary ligand and also coordination a water molecule to the metal ion [26]. A weak band observed at the low energy region of the spectrum at $520 \mathrm{~cm}^{-1}$ was assigned to the $v(\mathrm{M}-\mathrm{N})$. This thus confirms the coordination of the nitrogen atom of the primary ligand to the metal ion. However the $v(\mathrm{~V}=\mathrm{O})$ band was absent. According to Greenwood and Earnshaw, a sixth ligand may be weakly bonded trans to the $(\mathrm{V}=\mathrm{O})$ moiety and thus produce a distorted octahedral structure; with a concomitant reduction in the stretching frequency of the $(\mathrm{V}=\mathrm{O})$ bond. This they suggested may be interpreted in terms of electron donation from this sixth bond, thereby making the vanadium atom less able to accept charge from the oxygen of $(\mathrm{V}=\mathrm{O})$ and so reducing the bond order. Additionally previous reports have shown similar complexes to be polymeric, with the vanadium ion attaining 6-coordination by stacking, so that the sixth position of each vanadium is occupied by the oxygen from the $(\mathrm{V}=\mathrm{O})$ beneath [28] [29] [30].

\subsection{Electronic Spectrum and Magnetic Moment}

\subsubsection{Ligand}

The electronic spectra of the ligands exhibited bands in the ultraviolent region of the electromagnetic spectrum as a result of the major chromophores which exists on the ligands, Table 3. The spectrum of 2-amino-3-methylbutanoic acid elicited a band at $252 \mathrm{~nm}$ and was assigned to $n \rightarrow \pi^{*}$ transition. The spectrum of 1,10-phenantroline showed two intense bands 310 and $324 \mathrm{~nm}$ which corresponds to $n \rightarrow \pi^{*}$ and $\pi \rightarrow \pi^{*}$ transitions [24] [25]. For ethylenediamine the spectrum revealed a band at $495 \mathrm{~nm}$ attributable to $n \rightarrow \sigma^{*}$ transition [24] [25]. Evidence of coordination of the metal ion with the corresponding ligands was provided by the $d-d$ transitions of the metal ion observed in the complexes, which were absent in the ligands. Further corroborating coordination of the ligands 
Table 3. Relevant electronic spectra bands.

\begin{tabular}{ccc}
\hline Compound & Intraligand Band $(\mathrm{nm})$ & $d$ - $d$ bands $(\mathrm{nm})$ \\
\hline L1 & 252 & - \\
L2 & 310,324 & - \\
L3 & 495 & - \\
1 & 302 & $465,505,695$ \\
2 & 286 & 435 \\
$\mathbf{3}$ & 413 & 480 \\
$\mathbf{4}$ & 295,359 & 650,712 \\
$\mathbf{5}$ & 267,285 & 518,720 \\
$\mathbf{6}$ & 295,450 & 580,716 \\
\hline
\end{tabular}

to the metal ions were shifts observed in the bands observed in the ultraviolet region of the spectra of the coordination compounds in relation to that obtained for the free base [28].

\subsubsection{Chromium Complexes}

1) Compound 1: The electronic spectrum of this compound exhibited two sets of bands: a strong band at $302 \mathrm{~nm}$; one weak band at $465 \mathrm{~nm}$, two broad bands at 505 and $695 \mathrm{~nm}$. The strong band in the ultraviolet region was ascribed to the $n \rightarrow \pi^{*}$ transition of the ligand. This thus indicated a shift in this transition in comparison with the free base, 2-amino-3-methylbutanoic acid. On the other hand the other three bands were attributed to the ${ }^{4} \mathrm{~A}_{2 g}(\mathrm{~F}) \rightarrow{ }^{4} \mathrm{~T}_{1 \mathrm{~g}}(\mathrm{P}),{ }^{4} \mathrm{~A}_{2 g}(\mathrm{~F}) \rightarrow$ ${ }^{4} \mathrm{~T}_{1 \mathrm{~g}}(\mathrm{~F})$ and ${ }^{4} \mathrm{~A}_{2 \mathrm{~g}}(\mathrm{~F}) \rightarrow{ }^{4} \mathrm{~T}_{2 \mathrm{~g}}(\mathrm{~F})$ transitions characteristic of $\mathrm{d}^{3} \mathrm{Cr}(\mathrm{III})$ configuration, suggestive of an octahedral geometry. This is in agreement with previous studies [31] [32] [33]. The observed magnetic moment at 3.14 BM is close to the spin only magnetic moment for $\mathrm{Cr}(\mathrm{III})$ with $\mathrm{d}^{3}$ configuration, but lower than that expected for this configuration [32] [33]. This may be ascribed to antiferromagnetism, suggesting that the $\mathrm{Cr}(\mathrm{III})$ ion has its spins aligned in opposite directions [32]. Compound 1: The electronic spectrum of this compound exhibited two sets of bands: a strong band at $302 \mathrm{~nm}$; one weak band at $465 \mathrm{~nm}$, two broad bands at 505 and $695 \mathrm{~nm}$. The strong band in the ultraviolet region was ascribed to the $n \rightarrow \pi^{*}$ transition of the ligand. This thus indicated a shift in this transition in comparison with the free base, 2-amino-3-methylbutanoic acid. On the other hand the other three bands were attributed to the ${ }^{4} \mathrm{~A}_{2 \mathrm{~g}}(\mathrm{~F}) \rightarrow{ }^{4} \mathrm{~T}_{1 \mathrm{~g}}(\mathrm{P}),{ }^{4} \mathrm{~A}_{2 g}(\mathrm{~F}) \rightarrow{ }^{4} \mathrm{~T}_{1 \mathrm{~g}}(\mathrm{~F})$ and ${ }^{4} \mathrm{~A}_{2 \mathrm{~g}}(\mathrm{~F})$ $\rightarrow{ }^{4} \mathrm{~T}_{2 \mathrm{~g}}(\mathrm{~F})$ transitions characteristic of $\mathrm{d}^{3} \mathrm{Cr}(\mathrm{III})$ configuration, suggestive of an octahedral geometry. This is in agreement with previous studies [31] [32] [33]. The observed magnetic moment at $3.14 \mathrm{BM}$ is close to the spin only magnetic moment for $\mathrm{Cr}$ (III) with $\mathrm{d}^{3}$ configuration, but lower than that expected for this configuration [32] [33]. This may be ascribed to antiferromagnetism, suggesting that the $\mathrm{Cr}(\mathrm{III})$ ion has its spins aligned in opposite directions [32].

2) Compound 2: The spectrum of this compound elicited two bands, one intense band at $286 \mathrm{~nm}$ assigned to $n \rightarrow \pi^{*}$ transition and a broad band at $435 \mathrm{~nm}$ attributable to the $d-d$ transition of the metal ion and ascribed to ${ }^{4} \mathrm{~A}_{2 g}(\mathrm{~F}) \rightarrow$ ${ }^{4} \mathrm{~T}_{1 \mathrm{~g}}(\mathrm{~F})$ transition, suggestive of an octahedral geometry [32] [33]. Its magnetic 
moment 3.84 BM, is consistent with the spin-only magnetic moment of $3.87 \mathrm{BM}$ for an octahedral geometry for a $\mathrm{d}^{3}$ electron configuration system. It therefore corroborates an octahedral geometry for compound 2 [32].

3) Compound 3: Similar to that of compound 2, two bands were also observed for this complex at 413 and $480 \mathrm{~nm}$. These were assigned to $\pi \rightarrow \pi^{*}$ intra-ligand transition and ${ }^{4} \mathrm{~A}_{2 \mathrm{~g}} \rightarrow{ }^{4} \mathrm{~T}_{1 \mathrm{~g}}(\mathrm{~F}), d-d$ transition respectively [32] [33], thus suggestive of an octahedral geometry for $\mathrm{Cr}$ (III) ion. Its magnetic moment of 3.84 BM further supports an octahedral geometry [32].

\subsubsection{Oxovanadium Complexes}

1) Compound 4: The electronic spectrum of compound 4, exhibited four bands. Two intense bands were observed at 295 and $359 \mathrm{~nm}$ and were assignable to $n \rightarrow \pi^{*}$ and $\pi \rightarrow \pi^{*}$ intra-ligand transitions. It also showed two broad bands at 650 and $712 \mathrm{~nm}$ ascribed to ${ }^{2} \mathrm{~B}_{2} \rightarrow{ }^{2} \mathrm{E}$ and ${ }^{2} \mathrm{~B}_{2} \rightarrow{ }^{2} \mathrm{~B}_{1}, d-d$ transitions [24] [25] [32]. According to previous reports this indicates a square pyramidal geometry. Its magnetic moment of $1.75 \mathrm{BM}$ is characteristic of a square pyramid geometry for $\mathrm{V}(\mathrm{IV})$ ion. This is therefore corroborates of a square pyramid geometry for compound 4.

2) Compound 5: The spectrum of this compound displayed five bands. Two intense band and a medium band observed at 267, 285, $315 \mathrm{~nm}$ respectively, and they are attributed to $n \rightarrow \sigma^{*}, n \rightarrow \pi^{*}$ and $\pi \rightarrow \pi^{*}$ intra-ligand transitions of the ligands [24] [25]. The spectrum also exhibited two broad bands, at 518 and 720 $\mathrm{nm}$; this is ascribable to ${ }^{2} \mathrm{~B}_{2} \rightarrow{ }^{2} \mathrm{E}$ and ${ }^{2} \mathrm{~B}_{2} \rightarrow{ }^{2} \mathrm{~B}_{1} d-d$ transitions [32]. This corresponds to a square pyramid geometry for $\mathrm{VO}(\mathrm{IV})$ ion. A magnetic moment of 1.97 BM was obtained for compound 5, this is slightly higher than the spin only value of $1.73 \mathrm{BM}$. And is consistent with a $d^{\mathbb{A}}$ electron configuration for vanadium(IV). The increment in the magnetic moment may however be ascribed to orbital contribution [32] [34] [36]. Furthermore prior workers on oxovanadium(IV) ion have interpreted this magnetic moment to be suggestive of a square pyramid geometry around the oxovanadium(IV) ion. Therefore a square pyramidal geometry is proposed for compound 5 .

3) Compound 6: The spectrum of this complex displayed three bands: an intense band at $295 \mathrm{~nm}$ and two medium bands at 387 and $450 \mathrm{~nm}$, which were assigned to $n \rightarrow \pi^{\star}, n \rightarrow \sigma^{\star}$ and $\pi \rightarrow \pi^{*}$ intraligand transitions respectively [24] [25]. The spectrum also exhibited two broad bands at 580 and $716 \mathrm{~nm}$ corresponding to ${ }^{2} \mathrm{~B}_{2} \rightarrow{ }^{2} \mathrm{E}$ and ${ }^{2} \mathrm{~B}_{2} \rightarrow{ }^{2} \mathrm{~B}_{1} d-d$ transitions, for vanadium(IV) [32]. A magnetic moment of $2.03 \mathrm{BM}$ was obtained for this compound. This is higher than the spin only value of $1.73 \mathrm{BM}$. However, earlier workers have interpreted this to be consistent with an octahedral geometry for vanadium(IV) ion. We propose therefore an octahedral geometry for this compound [34] [35]. This is in good agreement with the result obtained for this compound from the infrared analysis.

In this present work, based on the results obtained an octahedral geometry is proposed for the $\mathrm{Cr}$ (III) complex for the binary complex, bis(2-amino-3-me- 
thylbutanoic acid)chromium(III) complex. It is suggested that the 2-amino-3methylbutanoic acid free base coordinated via the nitrogen atom of the amino substituent and one oxygen atom of the carboxylate ion. This was suggested as a result of the difference observed in the values for $v_{\text {sym }}\left(\mathrm{COO}^{-}\right)$and $v_{\text {asym }}\left(\mathrm{COO}^{-}\right)$, which suggested the monodentate nature of the carboxylate substituent of the ligand [9] [26]. This is also in good agreement with previous reports. These results thus indicated that 2-amino-3-methylbutanoic acid coordinated in a bidentate fashion, binding in the ratio 1:2, metal ligand ratio. We propose further that the central $\mathrm{Cr}$ (III) ion coordinated additionally to two water molecules from the reaction solvent, to achieve an octahedral geometry. For the formation of the mixed ligand chromium(III) complexes, the primary ligand, 2-amino-3-methylbutanoic acid, coordinated in a similar way as in the binary complex. On the other hand, both secondary ligands coordinated in a bidentate manner with 1,10-phenantroline coordinating via the two heteroaromatic nitrogen atoms and ethylenediamine forming the complex using the two nitrogen atoms of the amino moiety. Similar to the binary $\mathrm{Cr}$ (III) complex, the $\mathrm{Cr}$ (III) ternary complexes existed in an octahedral geometry, with two additional water molecules coordinated to the $\mathrm{Cr}$ (III) ion at the apical region of the complexes. This was further confirmed by the results obtained from the metal analyses of the complexes, Table 1 . Therefore we propose that the structure assumed by compounds $\mathbf{1}-\mathbf{3}$ may be represented by Figures 4-6 respectively. An octahedral geometry is generally more favourable for chromium(III) complexes, as a result of the three electrons in the $3 \mathrm{~d}$ orbital of $\mathrm{Cr}(\mathrm{III})$, these will first singly fill the lower energy three $\mathrm{t}_{2} \mathrm{~g}$ orbitals, as a result of the stability of this configuration [32].

The results obtained for the oxovadium(IV) complexes suggested that the primary ligand 2-amino-3-methylbutanoic and the secondary ligands 1,10-phenantroline and ethylenediamine coordinated in a similar manner as in the $\operatorname{Cr}(\mathrm{III})$ ion. However a square pyramidal monomeric geometry was assumed in the case of compounds 4 and 5. A distorted octahedral geometry was however proposed for compound 6 . The percentage metal analyses was corroborative of this geometry

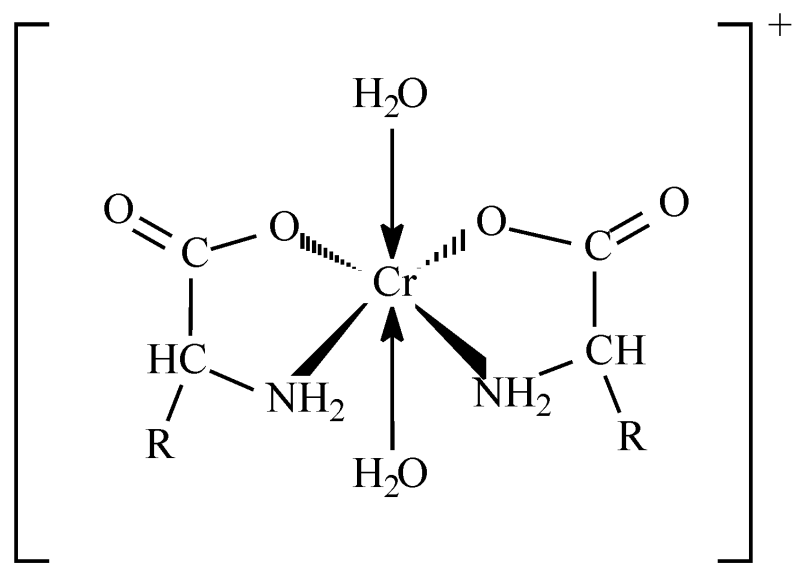

Figure 4. Compound 1. 


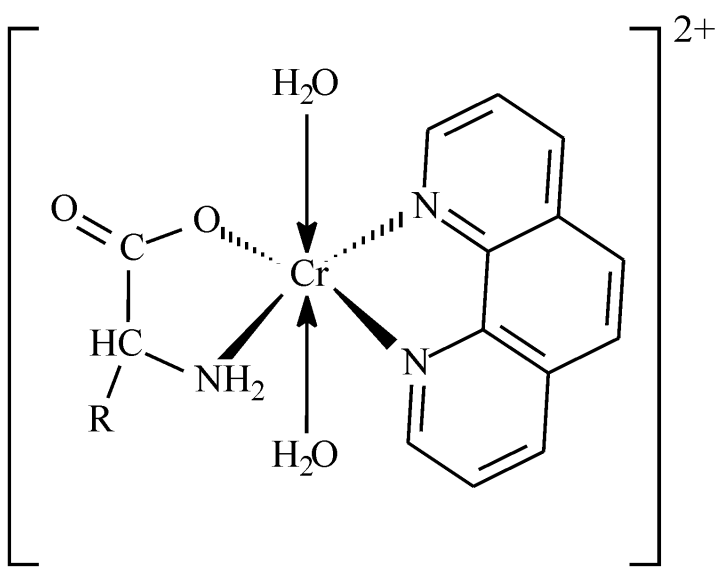

Figure 5. Compound 2.

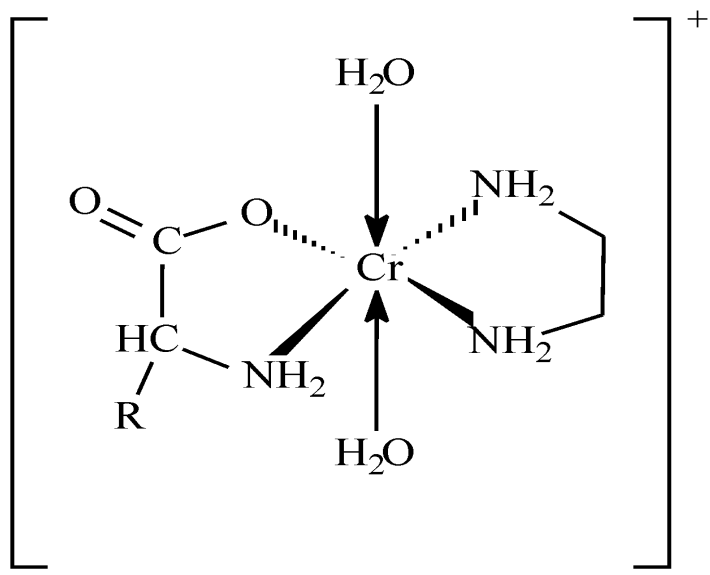

Figure6. Compound 3.

and suggested the formulations for compound 4 and 5 to be given by $\mathrm{VO}(\mathrm{L} 1)_{2}$ and $[\mathrm{VO}(\mathrm{L1})(\mathrm{L} 2)]_{2} \mathrm{SO}_{4}$, which may be depicted by Figure 7 and Figure 8 respectively. Furthermore compound 6 may be represented by $\left.\mathrm{VO}(\mathrm{L} 1)(\mathrm{L} 3)\left(\mathrm{H}_{2} \mathrm{O}\right)\right]_{2} \mathrm{SO}_{4}$ and illustrated structurally by Figure 9 .

\subsection{Antibacterial Activity}

\subsubsection{Zones of Inhibition of Bacteria Growth}

The synthesized compounds were tested for their antibactebial activity by testing them against eight microbes, three gram positive bacteria namely: $S$. aureus (NCIB 8585), B. subtilis (NCIB 6639) and B. cereus (NCIB 6349); five gram negative bacteria, $P$. aeruginosa (NCIB 950), $P$. fluorescence (NCIB 3756), E. coli (NCIB 86), K. pneunoniae (NCIB 418) and $P$. vulgaris (NCIB 67). The zones of inhibition of the tested microbial growth as a result of the synthesized compounds were determined and the results obtained are presented in Table 4 . The results indicated that compounds $\mathbf{2 ,} \mathbf{4}$ and 5 exhibited from weak, moderate to remarkable activity against the tested microbes. Compounds $\mathbf{2}$ and $\mathbf{5}$ exhibited significantly better activity, $(\mathrm{P}<0.05)$, against $E$. coli and $K$. pneunoniae, both gram negative bacteria, relative to the standard, streptomycin. This result thus 


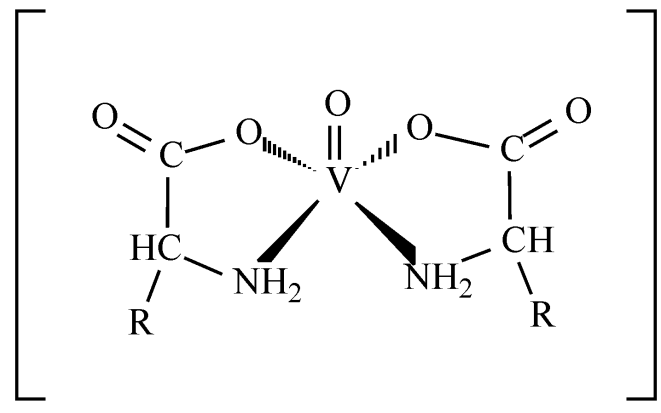

Figure 7. Compound 4.

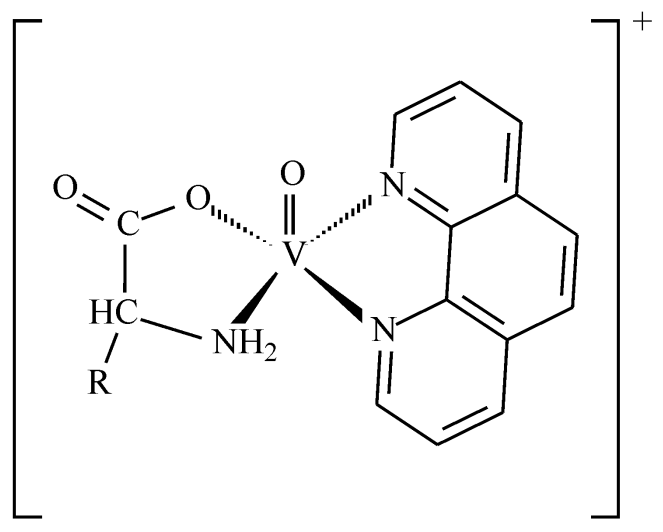

Figure 8. Compound 5.

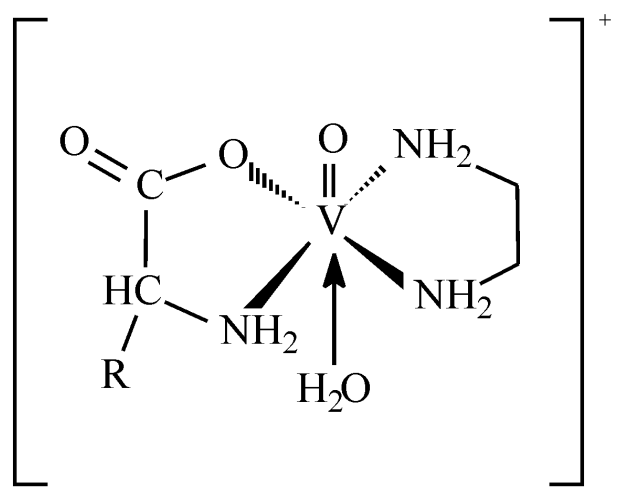

Figure 9. Compound 6.

Table 4. Result of zone of antimicrobial inhibition ( $\mathrm{mm}$ ) for the ligands and complexes.

\begin{tabular}{ccccccccccc}
\hline Organism & L1 & L2 & L3 & $\mathbf{1}$ & $\mathbf{2}$ & $\mathbf{3}$ & $\mathbf{4}$ & $\mathbf{5}$ & $\mathbf{6}$ & C \\
\hline P. aeruginosa & - & 24 & - & - & 04 & - & - & 20 & - & 31.5 \\
P. fluorescence & - & 10 & - & - & 22 & - & - & 18 & - & 50 \\
S. aureus & - & 34 & - & - & 31 & - & - & 24 & - & 38 \\
B. subtilis & - & 28 & - & - & - & - & - & 15 & - & 34 \\
E. coli & - & 23 & - & - & 20 & - & 04 & 10 & - & - \\
K. pneunoniae & - & 32 & - & - & 28 & - & - & 34 & - & 10 \\
P. vulgaris & - & 42 & - & - & 39 & - & 16 & 36 & - & 62 \\
B. cereus & - & - & - & - & - & - & - & - & - & 68 \\
\hline
\end{tabular}

$\mathrm{C}=$ Streptomycin 
suggests the potency of these compounds and their good candidacy as leads as antibacterial agents against both microbes.

For the binary complexes, only compound 4 exhibited any activity against the tested microbes. This vanadyl complex exhibited weak activity against $E$. coli and $P$. vulgaris, but its chromium(III) counterpart had no effect on the tested organisms. Such better activity of the bis(2-amino-3-methylbutanoic acid)oxovanadium(IV) complex in comparison with its chromium(III) counterpart indicates the better activity of the vanadyl ion as an antibacterial agent in this case. Both mixed ligand complexes of 2-amino-3-methylbutanoic acid with 1,10-phenantroline, also displayed significant activity $(\mathrm{P}<0.05)$, against both gram positive and gram negative bacteria, indicating the broad spectrum of activity of both compounds against the tested microbes. However, both compounds exhibited varied activity with each microbe [36] [37]. Although both mixed ligand complexes of 1,10phenantroline elicited good antibacterial activities, however both $\mathrm{Cr}$ (III) and $\mathrm{VO}(\mathrm{IV})$ mixed ligand complex of 2-amino-3-methylbutanoic acid with ethylenediamine had no effect on the tested microbes. This may be ascribed on one hand to the better antibacterial activity of 1,10-phenantroline [13] [17]. It can be inferred from the results obtained that the use of 1,10-phenantroline in the formation of the mixed ligand compounds $\mathbf{2}$ and 5 brought additive effect of its antibacterial potential on both adducts [13] [17]. On the other hand, structurally 1,10phenantroline is a hydrophobic heteroaromatic compound, as against ethylenediamine which is a straight chain hetero-compound, as such it may be considered that it may have increased the liposolubility of both adducts and therefore enhanced the penetration of these compounds through the lipid membrane of the gram positive bacteria. Thus, this resulted to the better activity of both compounds, relative to their ethylenediamine counterpart, thereby further validating the antibacterial potency of 1,10-phenantroline and the plausible additive ability of this molecule in enhancing the antibacterial activity of mixed ligand complexes [6] [13] [17] [18] [36] [37].

The zone of inhibition values obtained for 2-amino-3-methylbutanoic acid are lower than those of compounds 2, 4 and 5 against most of the micro-organisms, indicating that these compounds are more potent than this ligand as antibacterial agent. This observed disparity in their effectiveness against the tested bacteria may be ascribed to either the enhanced ability, as a result of coordination, of these compounds to permeate the cell walls of the microbes or the difference in the ribosomes of the microbial cells [6] [36] [37]. The results obtained, Table 4, also indicated that 1,10-phenantroline, one of the secondary ligands, exhibited in some cases significant activity $(\mathrm{P}<0.05)$, against the tested microbes, and in some cases more active than the standard. The most sensitive strains were the bacteria species $E$. coli and $K$. pneunoniae. This result is in agreement with what was obtained by Gaëlle and co-workers [38].

\subsubsection{Minimum Inhibitory Concentration}

The antimicrobial activities of some of the complexes were quantified by the 
Table 5. Result of minimum inhibitory concentration.

\begin{tabular}{cccc}
\hline Organism & $\mathbf{2}$ & $\mathbf{4}$ & $\mathbf{5}$ \\
\hline P. aeruginosa & 05 & 05 & 1.78 \\
P. fluorescence & 2.5 & 05 & 0.875 \\
S. aureus & 1.75 & 05 & 0.875 \\
B. subtilis & - & 05 & 0.875 \\
E. coli & 0.875 & 0.875 & 0.875 \\
K. pneunoniae & 2.5 & 05 & 0.875 \\
P. vulgaris & 2.5 & 05 & 0.875 \\
B. cereus & - & 05 & 0.875 \\
\hline
\end{tabular}

determination of their MICs. The MIC indicates the lowest drug concentration at which a visible inhibition growth of the microorganisms is noticed. The values for the different pathogens were determined by using the micro broth dilution test [23] [38]. The MIC values for compounds $\mathbf{2}, \mathbf{4}$ and $\mathbf{5}$ are presented in Table 5. This was as a result of their relative better and significant activity in comparison with the other compounds. Compounds $\mathbf{2}$ and $\mathbf{5}$ exhibited a broad spectrum of activity, as a result of their high activity towards all the tested strains. Compound 5 elicited the least minimum inhibitory concentration for all the compounds. This result therefore suggests that low concentrations of this complex may not only inhibit the growth of microorganisms, but also kill them. As a consequence, therefore it suggests that it may have both bacteriostatic and bactericidal effects [38] [39] [40].

\section{Conclusion}

Coordination compounds of 2-amino-3-methylbutanoic acid and its 1,10-phenantroline and ethylenediamine adducts were synthesized with chromium(III) and oxovanadium(IV) ions. The compounds were investigated for their structural and antibacterial activity. The results obtained suggested an octahedral geometry for all the chromium(III) complexes. A square pyramid geometry was proposed for the bis(2-amino-3-methylbutanoic acid)oxovanadium(IV) complex and the 1,10-phenantroline adduct of oxovanadium(IV). However, an octahedral geometry was proposed for the oxovanadium(IV) ethylenediamine adduct. The antibacterial studies indicated that the 1,10-phenantroline adduct for both oxovanadium(IV) and chromium(III) complexes elicited significant antibacterial activity. They exhibited better activity against the standard, streptomycin, against $E$. coli and $K$. pneunoniae. The oxovanadium 1,10-phenantroline adduct also gave the lowest minimum inhibitory concentration for all the tested microbes. This thus suggested that this compound may serve as a lead compound as antibacterial agent against $E$. coli and $K$. pneunoniae.

\section{Conflicts of Interest}

The authors declare no conflicts of interest regarding the publication of this paper. 


\section{References}

[1] Ferell, N.P. (2003) Metal Complexes as Drugs and Chemotherapeutic Agents. In: Comprehensive Coordination Chemistry II, Volume 9, Elsevier, Amsterdam, 809-847. https://doi.org/10.1016/B0-08-043748-6/09021-6

[2] Selvaganapathy, M. and Raman, N. (2016) Pharmacological Activity of a Few Transition Metal Complexes: A Short Review. Journal of Chemical Biology and Therapeutics, 1, 1-10.

[3] Haas, K.L. and Franz, K.J. (2009) Application of Metal Coordination Chemistry to Explore and Manipulate Cell Biology. Chemical Review, 109, 4921-4960. https://doi.org/10.1021/cr900134a

[4] Anitha, C., Sumathi, S., Tharmaraj, P. and Sheela, C.D. (2011) Synthesis, Characterization, and Biological Activity of Some Transition Metal Complexes Derived from Novel Hydrazone Azo Schiff Base Ligand. International Journal of Inorganic Chemistry, 2011, Article ID: 493942. https://doi.org/10.1155/2011/493942

[5] Slavin, Y.N., Asnis, J., Häfeli, U.O. and Bach, H. (2017) Metal Nanoparticles: Understanding the Mechanisms Behind Antibacterial Activity. Journal of Nanobiotechnology, 15, 1-20. https://doi.org/10.1186/s12951-017-0308-Z

[6] Chohan, Z.H., Farooq, M.A., Scozzafava, A. and Supuran, C.T. (200) Antibacterial Schiff Bases of Oxalyl-Hydrazine; Diamide Incorporating Pyrrolyl and Salicylyl Moieties and of Their Zinc(II). Journal of Enzyme Inhibition and Medicinal Chemistry, 17, 1-7. https://doi.org/10.1080/14756360290005598

[7] Kan, Y.K., Hsu, Y.L., Chen, Y.H., Chen, T.C., Wang, J.Y. and Kuo, P.L. (2013) Gemifloxacin, a Fluoroquinolone Antimicrobial Drug, Inhibits Migration and Invasion of Human Colon Cancer Cells. BioMedical Research International, 2013, 1-11. https://doi.org/10.1155/2013/159786

[8] Patel, R.N., Singh, N., Shukla, K.K., Gundla, V.L.N. and Chauhan, U.K. (2006) Synthesis, Characterization and Biological Activity of Ternary Copper(II) Complexes Containing Polypyridyl Ligands. Spectrochimica Acta, Part A, 63, 21-26. https://doi.org/10.1016/j.saa.2005.04.030

[9] Aiyelabola, T., Akinkunmi, E., Obuotor, E., Olawuni, I., Isabirye, D. and Jordaan, J. (2017) Synthesis Characterization and Biological Activities of Coordination Compounds of 4-Hydroxy-3-Nitro-2H-Chromen-2-One and Its Aminoethanoic Acid and Pyrrolidine-2-Carboxylic Acid Mixed Ligand Complexes. Bioinorganic Chemistry and Applications, 2017, Article ID: 6426747. https://doi.org/10.1155/2017/6426747

[10] Efthimiadou, E.K., Katsarou, M.E., Karaliota, A. and Psomas, G. (2008) Copper(II) Complexes with Sparfloxacin and Nitrogen-Donor Heterocyclic Ligands: Structure-Activity Relationship. Journal of Inorganic Biochemistry, 102, 910-920. https://doi.org/10.1016/j.jinorgbio.2007.12.011

[11] Efthimiadou, E.K., Thomadaki, H., Sanakis, Y., Raptopoulou, C.P., Katsaros, N., Scorilas, A., Karaliota, A. and Psomas, G. (2007) Structure and Biological Properties of the Copper(II) Complex with the Quinolone Antibacterial Drug N-Propyl-Norfloxacin and 2,2'-Bipyridine. Journal of Inorganic Biochemistry, 101, 64-73. https://doi.org/10.1016/j.jinorgbio.2006.07.019

[12] Katsarou, M.E., Efthimiadou, E.K., Psomas, G., Karaliota, A. and Vourloumis, D. (2008) Novel Copper(II) Complex of N-Propyl-Norfloxacin and 1,10-Phenan- throline with Enhanced Antileukemic and DNA Nuclease Activities. Journal of Medicinal Chemistry, 51, 470-478. https://doi.org/10.1021/jm7013259

[13] Dar, O.A., Lone, S.A., Malik, M.A., FM.. Aqualan, Wani, M.Y. and Hashmi, A.A. 
(2019) Synthesis and Synergistic Studies of Isatin Based Mixed Ligand Complexes as Potential Antifungal Theurapeutic Agent. Heliyon, 5, 1-8. https://doi.org/10.1016/j.heliyon.2019.e02055

[14] Sakr, S., Elshafie, H.S., Camele, I. and Sadeek, S.A. (2018) Synthesis, Spectroscopic, and Biological Studies of Mixed Ligand Complexes of Gemifloxacin and Glycine with $\mathrm{Zn}(\mathrm{II}), \mathrm{Sn}(\mathrm{II})$ and Ce(III). Molecules, 23, 1-17. https://doi.org/10.3390/molecules23051182

[15] Malik, M.A., Dar, O.A., Gull, P., Wani, M.Y. and Hashmi, A.A. (2018) Heterocyclic Schiff Base Transition Metal Complexes in Antimicrobial and Anticancer Chemotherapy. Medicinal Chemistry Communication, 1, 409-436. https://doi.org/10.1039/C7MD00526A

[16] Viganar, L., Galdino, A.C.M., Nunes, A.P., et al. (2016) Anti-Pseudomonas Aeruginosa Activity of 1,10-Phenantroline-Based Drugs against Both Planktonic- and Biofilm-Growing Cells. Journal of Antimicrobial Chemotherapy, 71, 128-134.

[17] Abebe, A. and Hailemariam, T. (2016) Synthesis and Assessment of Antibacterial Activities of Ruthenium(III) Mixed Ligand Complexes Containing 1,10-Phenantroline and Guanide. Bioinorganic Chemistry And Applications, 2016, 1-9. https://doi.org/10.1155/2016/3607924

[18] Amani, V., Safari, N., Khavasi, H.R. and Mirzaei, P. (2007). Iron(III) Mixed-Ligand Complexes: Synthesis, Characterization and Crystal Structure Determination of Iron(III) Hetero-Ligand Complexes Containing 1,10-Phenanthroline, 2,2'-Bipyridine, Chloride and Dimethyl Sulfoxide, $\left[\mathrm{Fe}\left(\right.\right.$ phen) $\mathrm{Cl}_{3}$ (DMSO)] and [Fe(bipy) $\left.\mathrm{Cl}_{3}(\mathrm{DMSO})\right]$. Polyhedron, 26, 4908-4914. https://doi.org/10.1016/j.poly.2007.06.038

[19] Hogan, D.J. (1990) Allergic Contact Dermatitis to Ethylenediamine. A Continuing Problem. Dermatologic Clinic, 8, 133-136. https://doi.org/10.1016/S0733-8635(18)30536-9

[20] Adkis, A., Benali-Baitich, O., Khan, M.A. and Bouet, G. (2000) Synthesis, Characterization and the Thermal Behavior of Mixed Ligand Complexes of Cobalt(III) with Dimethylglyoxime and Some Amino Acids. Synthesis and Reactions in Inorganic Metals Organometallic and Nanomaterial Chemistry, 30, 1849-1858. https://doi.org/10.1080/00945710009351873

[21] Nomiya, K., Takahashi, S., Noguchi, R., Nemoto, S., Takayama, T. and Oda, M. (2000) Synthesis and Characterization of Water-Soluble Silver(I) Complexes with L-Histidine ( $\mathrm{H}_{2}$ his) And (S)-(-)-2-Pyrrolidone-5-Carboxylic Acid ( $\mathrm{H}_{2}$ pyrrld) Showing a Wide Spectrum of Effective Antibacterial and Antifungal Activities. Crystal Structures of Chiral Helical Polymers $[\mathrm{Ag}(\mathrm{Hhis})]_{n}$ and $\left\{[\mathrm{Ag}(\mathrm{Hpyrrld})]_{2}\right\}_{n}$ in The Solid State. Inorganic Chemistry, 39, 3301-3311. https://doi.org/10.1021/ic9905260

[22] Aiyelabola, T.O., Ojo, I.A. and Akinkunmi, E.O. (2012) Synthesis Characterization and Structural and Antimicrobial Studies of Coordination Compounds of Phenylalanine and Glycine. International Journal of Chemistry, 4, 49-59. https://doi.org/10.5539/ijc.v4n2p49

[23] Pasdar, H., Saghavaz, B.H., Foroughifar, N. and Davallo, M. (2017) Synthesis, Characterization and Antibacterial Activity of Novel 1,3-Diethyl-1,3-Bis(4-Nitrophenyl)Urea and Its Metal(II) Complexes. Molecules, 22, 1-10. https://doi.org/10.3390/molecules22122125

[24] Kemp, W. (1991) Infrared Spectroscopy. In: Organic Spectroscopy, Macmillan, Hong Kong, 19-98. https://doi.org/10.1007/978-1-349-15203-2 2 
[25] Pavia, D., Lampman, G. and Kriz, G. (2001) Introduction to Spectroscopy. A Guide for Students of Organic Chemistry. 3rd Edition, Brooks and Cole, New York, 22-368.

[26] Nakamoto, K. (2009) Complexes of Amino Acids. In Infrared and Raman Spectroscopy of Inorganic and Coordination Compounds: Applications In: Coordination, Organometallics and Bioinorganic Chemistry, 6th Edition, John Wiley and Sons, New York, 67-69.

[27] Bellamy, L.J. (1976) The Infrared Spectra of Complex Molecules. Chapman and Hall, London, United Kingdom, 1-190.

[28] Greenwood, N.N. and Earnshaw, A. (1997) Coordination Compounds. In: Chemistry of the Elements, 2nd Edition, Oxford, Butterworth-Heinemann, 1060-1090, 1290-1326.

[29] Pillai, S.I., Subramamian, S.P. and Kandaswamy, A. (2013) A Novel Insulin Mimetic Vanadium-Flavonol Complex: Synthesis, Characterization and the in Vitro Evaluation in STZ-Induced Rat. European Journal of Medicinal Chemistry, 63, 109-117. https://doi.org/10.1016/j.ejmech.2013.02.002

[30] Popp, C.J., Nelson, J.H. and Ragsdale, R.O. (1969) Thermodynamic and Infrared Studies of Tertiary Amine Oxides with Bis(2,4-Pentanedionatooxovanadium(IV). Journal of American Chemical Society, 91, 610-614. https://doi.org/10.1021/ja01031a015

[31] Isabirye, D.A., Naledi, S.H. and Aiyelabola, T.O. (2016) Synthesis and Structural Characterization of Cr(III) Complexes of Porphyrazine and Phthalocyanine Derivatives and the Kinetic Studies of Metalation and Redox Activity. Asian Journal of Chemistry, 29, 489-495. https://doi.org/10.14233/ajchem.2017.20204

[32] Miessler, G.L. and Tarr, D.A. (1999) Coordination Compounds. In: Inorganic Chemistry, Pearson Prentice Hall, New York, 315-316.

[33] Pethe, G.B., Yaul, A.R. and Aswar, A. (2011) Synthetic, Characterization and Catalytic Studies of Some Coordination Compounds Derived from Unsymmetrical Quadridentate Schiff Base Ligand Russian. Journal of General Chemistry, 81, 2304-2309. https://doi.org/10.1134/S1070363211110144

[34] Sakurai, H., Katoh, A. and Yoshikawa, Y. (2006) Chemistry and Biochemistry of Insulin-Mimetic Vanadium and Zinc Complexes. Trial for Treatment of Diabetes Mellitus. Bulletin of the Chemical Society of Japan, 79, 1645-1664. https://doi.org/10.1246/bcsj.79.1645

[35] Nejo, A.A., Kolawole, G.A., Opoku, A.R., Muller, C. and Wolowska, J. (2009) Synthesis, Characterization and Insulin-Enhancing Studies of Unsymmetrial Tetradentate Schiff-Base Complexes of Oxovanadium. Journal of Coordination Chemistry, 62, 3411-3424. https://doi.org/10.1080/00958970903104327

[36] Panchal, P.K., Parekh, H.M., Pansuriya, P.B. and Patel, M.N. (2006) Bactericidal Activity of Different Oxovanadium(IV) Complexes with Schiff Bases and Application of Chelation Theory. Journal of Enzyme Inhibition and Medicinal Chemistry, 21, 203-209. https://doi.org/10.1080/14756360500535229

[37] Yenikaya, C., Poyraz, M., Sarı, M., Demirci, F., İlkimen, H. and Büyükgüngör, O. (2009). Synthesis, Characterization and Biological Evaluation of a Novel $\mathrm{Cu}(\mathrm{II})$ Complex with the Mixed Ligands 2,6-Pyridinedicarboxylic Acid and 2-Aminopyridine. Polyhedron, 28, 3526-3532. https://doi.org/10.1016/j.poly.2009.05.079

[38] Gaëlle, D.S., Yufanyi, D.M., Jagan, R. and Agwara, M.O. (2016) Synthesis, Characterization and Antimicrobial Properties of Cobalt(II) and Cobalt(III) Complexes Derived from 1,10-Phenanthroline with Nitrate and Azide Co-Ligands. Cogent Che- 
mistry, 2, Article ID: 1253201. https://doi.org/10.1080/23312009.2016.1253201

[39] Montazerozohoria, M., Nasr-Esfahania, M., Hoseinpoura M., Naghihab, A. and Zahedia, S. (2014) Synthesis of Some New Antibacterial Active Cadmium and Mercury Complexes of 4-(3-(2-(4-(Dimethyl Aminophenyl Allylidene AminopropylImino)Prop-1-Ethyl)-N,N-Dimethyl Benzene Amine. Chemical Speciation and Bioavailability, 26, 240-248. https://doi.org/10.3184/095422914X14145135824213

[40] Páez, P.L., Bazán, C.M., Bongiovanni, M.E., Toneatto, J., Albesa, I., Becerra, M.C. and Argüello, G.A. (2013) Oxidative Stress and Antimicrobial Activity of Chromium(III) and Ruthenium(II) Complexes on Staphylococcus aureus and Escherichia coli. BioMedical Research International, 2013, Article ID: 906912.

https://doi.org/10.1155/2013/906912 